УДК 686.12.056

() А. І. Іванко, К.т.н, доцент, О. С. Марченко, студент, НТУУ «КПІ», Київ, Україна

\title{
ОБРІЗУВАННЯ АРКУШЕВИХ МАТЕРІАЛІВ У ПНЕВМАТИЧНИХ ТРАНСПОРТУВАЛЬНИХ СИСТЕМАХ
}

\author{
У статті розглянуто пневматичну систему для \\ транспортування аркушевого матеріалу у зону його \\ обрізування.
}

\section{Ключові слова: аркушевий матеріал; вакуумна камера; транспортувальна система; обрізування; дисковий ніж; самонаклад; приймальний стіл.}

\section{Постановка проблеми}

Між операційні процеси суттєво впливають на продуктивність роботи поліграфічних і пакувальних машин. Так процес транспортування аркушевого матеріалу починається 3 його відокремлення від стосу, переміщення в зону обробки та виведення на приймальний стіл.

В зоні обробки аркушевих матеріалів найбільш технологічно складною операцією $є$ обрізування. Для обрізування півфабрикатів використовують аркушерізальні, одноножові та картонорізальні машини $[1,2]$.

Аркушерізальні машини розрізують стрічку на окремі аркуші з рулону. Мірний циліндр з притискним роликом подає півфабрикат у зону різання. Різальна секція складається 3 рухомого ножа, що зафіксований на барабані, і нерухомого протиножа. Нерухомий протиніж забезпечує послідовне ножичне різання картону. Для якісного різання потрібно обертовий ніж встановлювати під ку- том у двох площинах. Спочатку відносно твірної, а потім відповідно до осі обертового барабана. Протиніж встановлюється під кутом до напрямку транспортування матеріалу. Взаємодія обертового ножа та протиножа можлива лише після ретельного їх налагодження.

Операція розрізування гофрокартону виконується у картонорізальних машинах [2, 3]. До складу різальної секції входять дискові різальні інструменти. Вивідні валики подають аркуш у різальну секцію, яка складається з чашкових ножів. Картон може розрізатися у поздовжньому напрямку на заготовки визначеної ширини. Для розрізування картону створюється контакт чашкових інструментів торцевими площинами з радіальним перекриттям.

Для якісного дорізування крайки аркушевого матеріалу аркушерізальні та картонорізальні машини у своєму арсеналі використовують контрножі (протиножі). Вони в свою чергу

(C) $2016 \mathrm{p}$. 


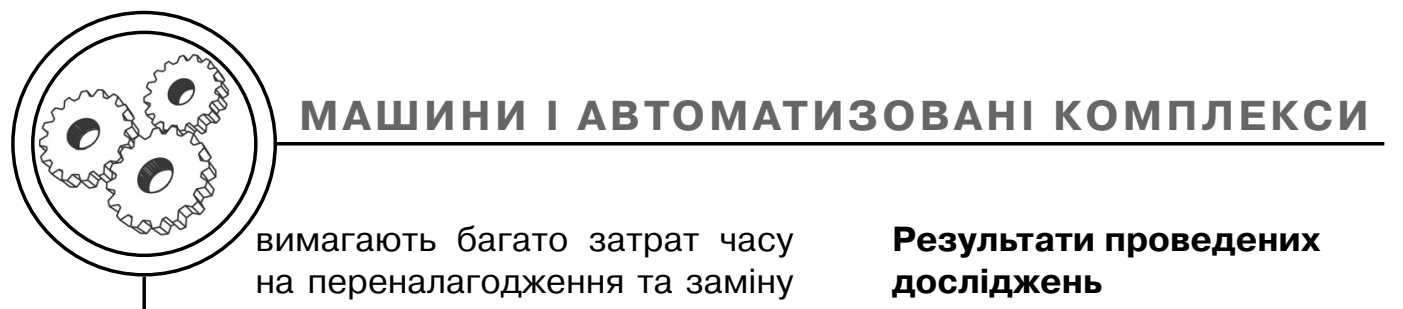
різальних інструментів.

\section{Аналіз попередніх досліджень}

Пристрій для обрізування аркушевого матеріалу може міститиу собі систему вирівнювання та зубчастопасові транспортери $[4,5]$. Транспортувальна система складається 3 інструментального вузла із закріпленим 3 гвинтовим ножем дозволяе здійснити розрізування аркушевого матеріалу.

Аркушевий матеріал подається в зону обрізування подавальним зубчастопасовим транспортером зі сталою швидкістю $V_{A}$ по проміжному столу в напрямку до інструментального вузла. За рахунок однакового напрямку обертання барабанів, взаємодії різального інструмента та протиножа забезпечується розрізування визначеної зони матеріалу.

При однаковому кроці різального інструмента і умові $\mathrm{V}_{\mathrm{A}}=\omega \cdot \mathrm{r}=$ const може відбуватися обрізування аркуша по визначеній лінії. Для забезпечення фігурної форми зрізу аркуш може рухатися із змінною швидкістю $\mathrm{V}_{\mathrm{A}}$.

\section{Мета роботи}

Метою даної роботи $є$ попереднє аналітичне визначення можливості безмарзанного способу обрізування аркушевого матеріалу, його транспортування та утримування в зоні різання за рахунок вакуумної камери.
Традиційне різання аркушевих картонних матеріалів чашковими ножами за наявності іх радіального перекриття складається 3 трьох фаз. В першу чергу це процес вдавлювання різальних крайок інструментів у матеріал, де відбувається ущільнення його структури. В подальшому відбувається прогин зовнішніх шарів матеріалу $\mathrm{i}$, як наслідок, зрізування його вздовж перетину різальними крайками.

Зусилля при якому відбувається обрізування аркушевого матеріалу становить:

$$
\mathrm{F}_{\mathrm{pi3}}=0,5 \frac{\Delta^{2} \cdot \tau_{\text {зр }} \cdot \varepsilon}{\operatorname{tg} \alpha},
$$

де $\Delta$ - товщина аркушевого матеріалу, $\tau_{\text {зр }}$ - середнє значення опору зрізування аркушевого матеріалу; $\varepsilon$ - відносна глибина надрізування картону перед початком кінцевого сколювання; $\alpha-$ кут між радіусом ножа в точці контакту з картоном і вертикаллю.

Проектування систем транспортування аркушевого матеріалу розрідженим повітрям ґрунтується на основі вакуумної камери (ВК). Конструктивно вакуумна камера з'єднується з вакуумним насосом, що відкачує повітря з камери. Таким чином створюється необхідний вакуум (розрідження). Аркушевий матеріал закриває собою визначену кількість отворів у робочій площині транспортування. Додатково у конструкції ВК можна передбачити використання ви- 
тяжних вентиляторів, що відкачують надлишкове повітря.

Створюється так зване розрідження повітря всередині камери, що призводить до виникнення утримуючої сили $\mathrm{F}_{3} . \mathrm{F}_{3}$ утримує аркушевий матеріал у робочій зоні під час транспортування. Через визначені отвори створений вакуум контролює позиціювання аркуша.

Відповідно для (маси 1 м², г q) картону формату A3 -

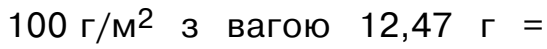
0,0124 кг сила, що необхідна для утримання матеріалу становитиме:

$$
F=m \cdot\left(g+\frac{a}{\mu}\right) \cdot S_{k},
$$

де $\mathrm{m}$ - маса матеріалу; g прискорення вільного падіння; a - прискорення системи; $\mu-$ коефіцієнт тертя; $S_{k}-$ коефіцієнт безпеки. Приймаємо: $\mathrm{m}=0,0124 \mathrm{\kappa г} ; \mathrm{g}=9,81 \mathrm{M} / \mathrm{c}^{2}$; $\mathrm{a}=1 \mathrm{~m} / \mathrm{c}^{2} ; \mu=0,6 ; \mathrm{S}_{\mathrm{k}}=1,7$. Таким чином:

$F=0,0124 \cdot\left(9,81+\frac{1}{0,6}\right) \cdot 1,7=0,242 \mathrm{H}$.

Для даного випадку приймаємо стрічку з кількістю отворами $\mathrm{n}=14$, діаметром $\mathrm{d}=10$ мм. Спочатку необхідно знайти площу одного отвору S.

$$
\mathrm{S}=\frac{\pi \cdot \mathrm{d}^{2}}{4}=78,5 \mathrm{MM}^{2}
$$

Загальна площа отворів становитиме $\mathrm{S}_{3}=\mathrm{S} \cdot \mathrm{n}$. Для нашої системи використовується дві стрічки, відповідно $\mathrm{n}=28$. Звідси $\mathrm{S}_{3}=78,5 \cdot 28=2198$ мм² $^{2}$.
Для даного аркушевого матеріалу загальна сила утримання становитиме:

$$
F_{3}=\frac{F}{S_{3}} .
$$

Підбір вакуумного насосу слід проводити для $\mathrm{F}_{3}=0,00011 \frac{\mathrm{H}}{\mathrm{MM}^{2}}$, або 110 Па. Виходячи 3 геометричних розмірів вакуумної камери $(\mathrm{L}=$ = 1,2 м- довжина; $A=0,05 \mathrm{M}-$ ширина; $\mathrm{H}=0,06$ м - висота), розраховуємо іï об'єм V= $=\mathrm{L} \cdot \mathrm{A} \cdot \mathrm{H}$.

Розрахунок часу вакуумування ємності проводимо для $\mathrm{V}=$ $=0,0036 \mathrm{M}^{3}$ :

$$
t=\left(\frac{V}{S}\right) \cdot \ln \left(\frac{p_{1}}{p_{2}}\right) \cdot F_{k},
$$

де $V=0,0036\left(\mathrm{M}^{3}\right)$ - об'єм камери; $\mathrm{S}=178\left(\mathrm{M}^{3} / г\right)-$ швидкість відкачування повітря; $\mathrm{p}_{1}=1000$ (мбар) - початковий тиск в камері; $p_{2}=1,1$ (мбар) - кінцевий тиск в камері; $F_{k}=3-$ поправочний коефіцієнт. Відповідно

$$
\begin{aligned}
& t=\left(\frac{0,0036}{178}\right) \cdot \ln \left(\frac{1000}{1,1}\right) \cdot 3= \\
& =0,00041 \text { год. }=1,48 \mathrm{c} .
\end{aligned}
$$

Для створення необхідного тиску в камері, який буде якісно утримувати і транспортувати вибраний аркушевий матеріал, знадобиться 1,48 с.

Проведені аналітичні дослідження виявили, що із збільшен-

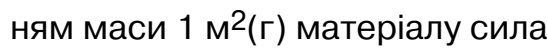
утримання $F_{3}$ при транспортуванні в різальній секції зростає. 


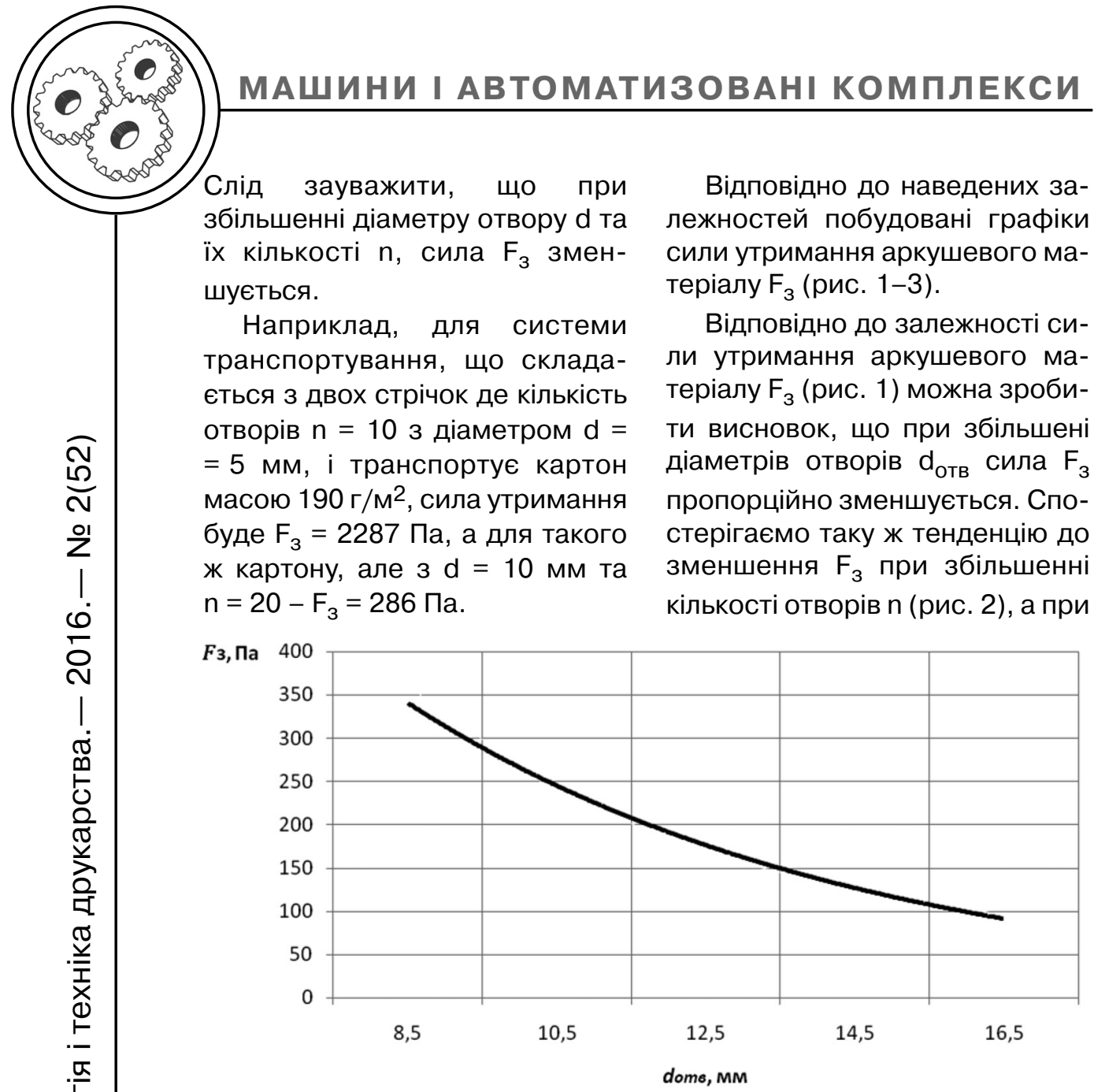

Рис. 1. Залежність сили утримання аркушевого матеріалу $F_{3}$ від діаметрів отворів $\mathrm{d}_{\text {отв }}$ при заданій однаковій їх кількості $(\mathrm{n}=20)$

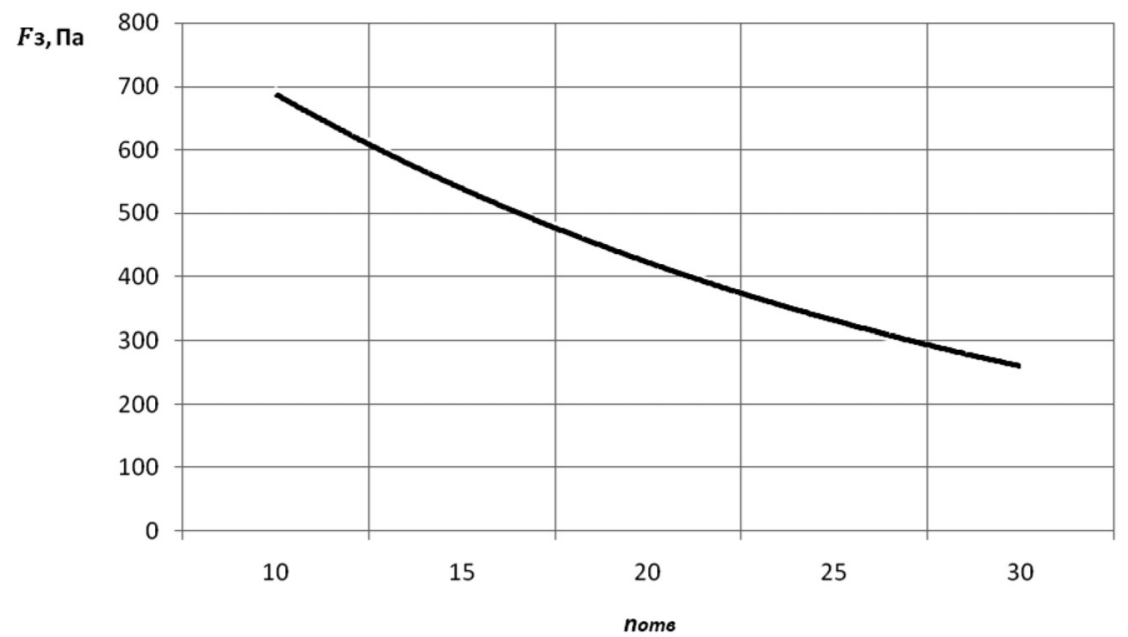

Рис. 2. Залежність сили утримання аркушевого матеріалу $F_{3}$ від кількості отворів n при заданому діаметрі $\mathrm{d}_{\text {отв }}=10 \mathrm{~mm} \mathrm{та} \mathrm{q}=260 \mathrm{r} / \mathrm{M}^{2}$ 


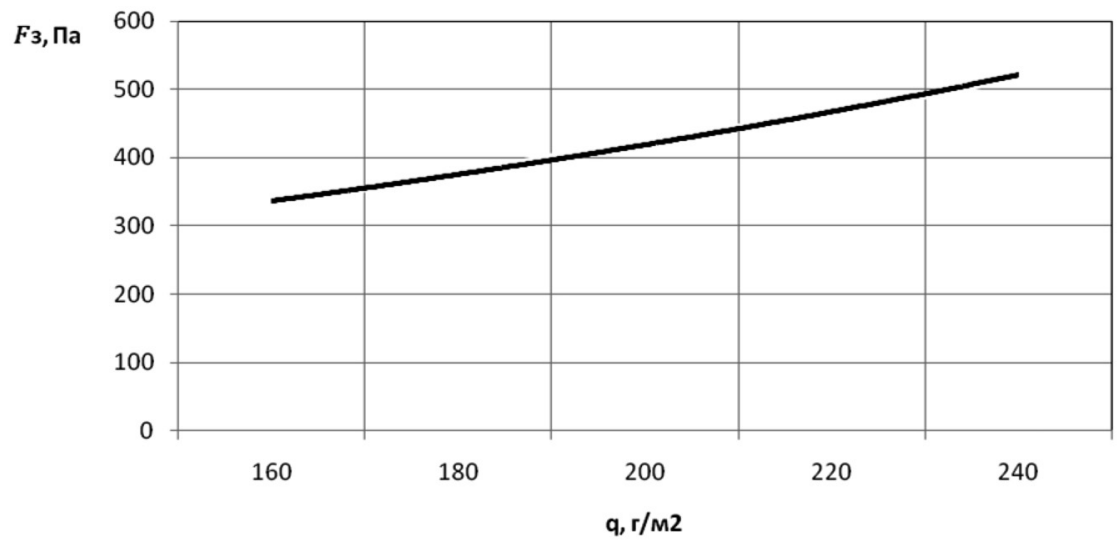

Рис. 3. Залежність сили утримання аркушевого матеріалу $F_{3}$ від його маси q (при $\mathrm{n}=20, \mathrm{~d}_{\text {отв }}=8,5$ мм)

збільшенні маси q необхідна сила утримання $F_{3}$ зростає (рис. 3).

\section{Висновки}

Перевагою вакуумного транспортування $є$ те, що на аркушевий матеріал не діють механічні сили, що суттєво технічно спрощують міжопераційні процеси. Крім того півфабрикати не деформуються і не пошкоджуються виконавчими елементами транспортерів.

Використання безмарзанного способу обрізування аркушевого матеріалу виключає контакт різального інструмента 3 протиножем чи контрножем. Оскільки лезо ножа контактує безпосередньо тільки з півфабрикатом, то можна припустити, що його затуплення зводиться до мінімуму, а модернізована конструкція транспортувальної системи значно спрощує виконання технологічного процесу обрізування.

\section{Список використаної літератури}

1. Топольницький П. В. Нові технології та пристрої для різання поліграфічних матеріалів та книжково-журнальних блоків : навч. посіб. / П. В. Топольницький, О. Б. Книш. - Львів : Афіша, 2003. - 88 с.

2. Регей І. І. Споживче картонне паковання (матеріали, проектування, обладнання для виготовлення) : навч. посіб. / Іван Іванович Регей. - Львів : УАД, 2011. - $144 \mathrm{c.}$

3. Хведчин Ю. Й. Брошурувально-палітурне устаткування. Ч. 2 : Палітурне устаткування : підручник / Ю. Й. Хведчин. - Львів : УАД, 2007. $392 \mathrm{c}$.

4. Пат. України на корисну модель № 98846. B31B1/14, B26D1/00. Пристрій для підготовки картонних боковинок фігурної палітурки / А. І. Іванко, Ю. О. Шостачук. - Заявл. 19.11.2014; Опубл. 12.05.2015. - Бюл. № 9, 2015. $-4 \mathrm{c}$.

5. Іванко А. І. Пристрій для фігурного обрізування аркушевих матеріалів в потокових лініях / А. І. Іванко, С. Л. Панов // Технологія і техніка друкарства. - К. : ВПІ НТУУ «КПІ». - 2015. - Вип. 4(50). - С. 105-110. Режим доступу : http://ttdruk.vpi.kpi.ua/article/view/54334. 
6. Юрьева А. В. Расчёт вакуумных систем : учебное пособие / А. В. Юрьева. - Томск : Изд-во Томского политехнического университета, 2012. $114 \mathrm{c}$.

\title{
References
}

1. Topolnytskyi, P. V. \& Knysh, O. B. (2003). Novi tekhnolohii ta prystroi dlia rizannia polihrafichnykh materialiv ta knyzhkovo-zhurnalnykh blokiv [New technologies and devices for cutting of printing materials and book-journal blocks]. Lviv: Afisha [in Ukrainian].

2. Rehei, I. I. (2011). Spozhyvche kartonne pakovannia (materialy, proektuvannia, obladnannia dlia vyhotovlennia) [Consumer carton packaging (materials, design, equipment for manufacturing)]. Lviv: UAD [in Ukrainian].

3. Khvedchyn, lu. I. (2007). Broshuruvalno-paliturne ustatkuvannia. Ch. 2 : Paliturne ustatkuvannia [Bindery equipment. Part 2: Binding-machinery and equipment]. Lviv: UAD [in Ukrainian].

4. Ivanko, A. I. \& Shostachuk, lu. O. Prystrii dlia pidhotovky kartonnykh bokovynok fihurnoi paliturky [Device for the preparation of cardboard of side notched cover] // Patent № UA98846. Publish 12.05.2015.

5. Ivanko, A. I. \& Panov, S. L. (2015). Prystrii dlia fihurnoho obrizuvannia arkushevykh materialiv v potokovykh liniiakh [Device for figure trimming of sheet materials in production lines]. Journal of Tekhnolohiia i tekhnika drukarstva Technology and Technique of Typography, 4(50), 105-110 [in Ukrainian]. Retrieved from http://ttdruk.vpi.kpi.ua/article/view/54334.

6. Yur'eva, A. V. (2012). Raschjot vakuumnyh sistem [Calculation of vacuum systems]. - Tomsk: Izd-vo Tomskogo politehnicheskogo universiteta [in Russian].

\section{В статье рассмотрена пневматическая система для транс- портировки листового материала в зону его обрезки.}

\section{Ключевые слова: листовой материал; вакуумная камера; транспортировочная система; обрезка; дисковый нож; самонаклад; приемный стол.}

The article deals with a pneumatic system for transporting the sheet material in its cutting area.

Keywords: sheet material; vacuum chamber; transporting system; cutting; circular cutter; sheet feeder; receiving table.

\author{
Рецензент - О. В. Зоренко, к.т.н., \\ доцент, НТУУ «КПІ»
}

Надійшла до редакції 06.06.16 